\title{
The Use of the Net Promoter Score (NPS) in an Outpatient Allergy and Pulmonary Clinic: An Innovative Look into Using Tablet-Based Tool vs Traditional Survey Method
}

This article was published in the following Dove Press journal:

Patient Related Outcome Measures

\author{
Abdullah Alismail (D) ${ }^{1,2, *}$ \\ Brett Schaeffer $\left(\mathbb{D}^{2, *}\right.$ \\ Andrea $\mathrm{Oh}^{\prime}$ \\ Saba Hamiduzzaman (1D ${ }^{3}$ \\ Noha Daher (D) \\ Hae-Young Song (iD ${ }^{2}$ \\ Brian Furukawa ${ }^{3}$ \\ Laren D Tan (iD) ${ }^{1-3}$ \\ 'Department of Cardiopulmonary \\ Sciences, School of Allied Health \\ Professions, Loma Linda University, Loma \\ Linda, CA, USA; ${ }^{2}$ Department of \\ Medicine, School of Medicine, Loma \\ Linda University, Loma Linda, CA, USA; \\ ${ }^{3}$ Division of Pulmonary, Critical Care, \\ Hyperbaric, Allergy and Sleep Medicine, \\ Loma Linda University Health, Loma \\ Linda, CA, USA; ${ }^{4}$ Department of Allied \\ Health Studies, School of Allied Health \\ Professions, Loma Linda University, Loma \\ Linda, CA, USA
}

*These authors contributed equally to this work

\begin{abstract}
Introduction: Patient satisfaction has become an essential metric in addition to the type of care they receive. Phone calls, emails, and text to patients after their healthcare visit are the typical way of obtaining the data reflecting patient satisfaction. The purpose of this retrospective quality improvement study is to compare the traditional post-outpatient clinic survey method with an onsite concise two-question survey using a tablet method immediately after the patient visit using Net Promoter Score (NPS) questions.
\end{abstract}

Methods: Data were collected retrospectively from February to August 2018 from an outpatient subspecialty clinic in southern California using an existing database from two different sources: the traditional method (TM) and the tablet-based tool (TBT), using NPS. The TM data were obtained from a third-party company using two questions via phone, email, and text collected 2-4 weeks after the patient's visit. The TBT has only two questions that were given to patients upon their visit check-out. These two questions assessed both provider and clinic's performance using the NPS method.

Results: In total, there were 1708 patients seen from February to August 2018. In the TM, the total outgoing messages during this period were $580(34.0 \%)$ with 156 responses $(27 \%)$. In the TBT, 648 out of $1708(37.9 \%)$ surveys were collected with a $100 \%$ response rate. The NPS score showed that $99.2 \%$ of the providers were promoters. The NPS score for the clinic was $96 \%$ which reflects a promoter score.

Conclusion: Our results indicate that when using the TBT immediately after their visit to the clinic, a higher response rate was noted. In addition, both methods had similar outcomes in terms of patient satisfaction NPS scores. Future prospective studies with a larger sample size are warranted to evaluate the effectiveness of the TBT tool in assessing patient satisfaction.

Keywords: patient satisfaction, NPS, Net Promoter Score

\section{Introduction}

Within the last two decades, patient satisfaction has been a driving force of quality improvement for healthcare associations and the development of the overall approach to patient care strategies. ${ }^{1}$ To improve service growth, and promote consumer loyalty, companies within the social and business sectors use patient satisfaction surveys to better achieve their vision and goals in a very competitive market. ${ }^{1-3}$ Since the 1990s, many healthcare clinics and hospitals use regular mail
Correspondence: Laren D Tan Division of Pulmonary, Critical Care, Hyperbaric, Allergy and Sleep Medicine, Loma Linda University Health, II 23 Anderson Street, Suite 6439, Loma Linda, CA 92354, USA

$\mathrm{Tel} / \mathrm{Fax}+|909558-808|$

Email LaTan@llu.edu 
or phone surveys to evaluate their patients' satisfaction and experience. $^{1,4,5}$ Sometimes, these traditional surveys were not administered until three weeks after the patient's visit. In addition, they were somewhat lengthy and timeconsuming to both the administrator and patients. ${ }^{4,5}$ The results of these types of surveys typically have a low response rate which makes it difficult to achieve an accurate assessment of the patients' experience and satisfaction regarding their visit. This dilemma with the traditional method is not siloed to healthcare clinics and hospitals, but also companies in the business sector. ${ }^{2}$

As society continues to change with advancements in technology, the healthcare sector, must also continue to adapt to creative methods in obtaining and evaluating patient satisfaction. In 2001, Bain \& Company developed a simple survey questionnaire that was scaled from 0 to 10 and was compiled to create the Net Promoter Score (NPS). ${ }^{2}$ Companies have used the NPS tool to identify loyal customers and assess project growth of their services. Due to its success, hundreds of companies in the business sector started using the NPS tool. ${ }^{3}$ Similarly, healthcare and other social sectors have also begun to incorporate the NPS tool into their clinics and hospitals to assess patient satisfaction with the provided services, patient loyalty, and growth. ${ }^{6-11}$

In the United States, Medicare started requiring hospitals and clinics to have patient satisfaction surveys collected as part of their quality measures for billing purposes. This has lead more clinics and hospitals to incorporate several tools to survey their patients and have this as part of their practice to receive full payment benefits. $^{12}$ In order to obtain patient satisfaction data, hospitals and clinics started utilizing questionnaires via phone or mail. ${ }^{4,5}$ Unfortunately, these tools were less efficient and ineffective due to a low response rate. ${ }^{13}$

The goal of this study was to compare a traditional institutional tool (phone, text messaging, and email) long survey questionnaire to an after-visit tablet tool using the NPS method in a concise two short question's survey. We hypothesized that the newer method using the NPS tool is non-inferior to the traditional phone survey for collecting patient satisfaction data. In addition, the tablet-based NPS method will provide a higher response rate compared to the traditional method.

\section{Methods}

This study was approved by Loma Linda University Health Institutional Review Board as an exempt quality improvement study. Data were extracted from two different sources (traditional method using phone, text, and email by a third-party vendor) and clinic tablet-based tool. Data from both methods were collected retrospectively from February 2018 to August 2018 as part of quality improvement to assess which method was more effective for the clinic and had a higher response rate from patients.

\section{Traditional Method (Using Phone, Text, and/or Email)}

This method was extracted from a third-party provider who collected the data from patients 2-4 weeks after their clinic visit using nine-question indicators that ranged from 0 to 10 or to answer "Yes, definitely," "Yes, somewhat," or "No". Later, the data were provided to each physician anonymously at the end of each month as feedback on their performance from the patients' perspective.

\section{Tablet-Based Tool}

The tablet-based tool (TBT) was designed using an online survey platform that has the NPS feature. After each visit, patients were given a tablet by the front desk team to answer two NPS questions using a 10-point Likert scale: - "How likely would you recommend our clinic to a friend or family?" and "How likely would you recommend clinician X to a friend or family?", prior to leaving the clinic by the front desk team, Figure 1.

The NPS tool is broken down into three different categories based on the selected answer by the respondent: 1) detractors (scores 0-6), passives (scores 7-8), and promoters (scores 9-10). Promoters signify the most enthusiastic and loyal customers, while detractors are seen as providing negative value towards a company. Passives are neither positive or negative and if they find another competitor clinic or physician, they may go with them.

An automatic trigger response was created as part of the tablet method within the survey to automatically send an alert email to the selected provider who took care of the patient if they scored anything that is less than 8 (passive OR detractor). This gives the provider quick and immediate feedback of the patient's experience before leaving the clinic.

The TBT method using NPS was compared to the traditional method (phone, email, and text) by comparing the number of outgoing messages.

In the traditional method, only two questions were used and compared with the TBT. These questions were as 


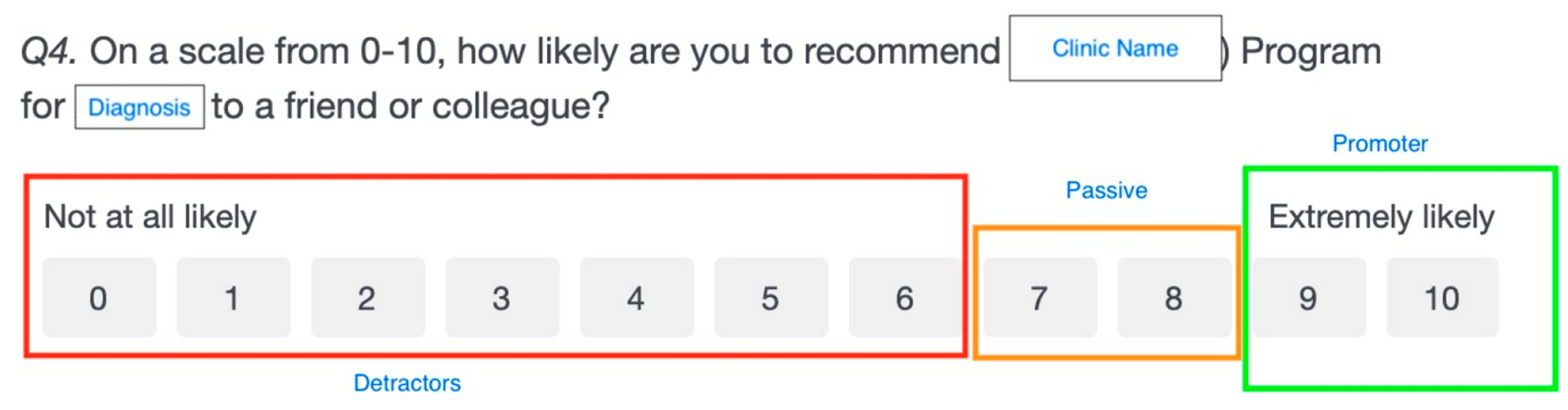

\section{Q5. On a scale from 0-10, how likely are you to recommend Physician Name a friend or} family?

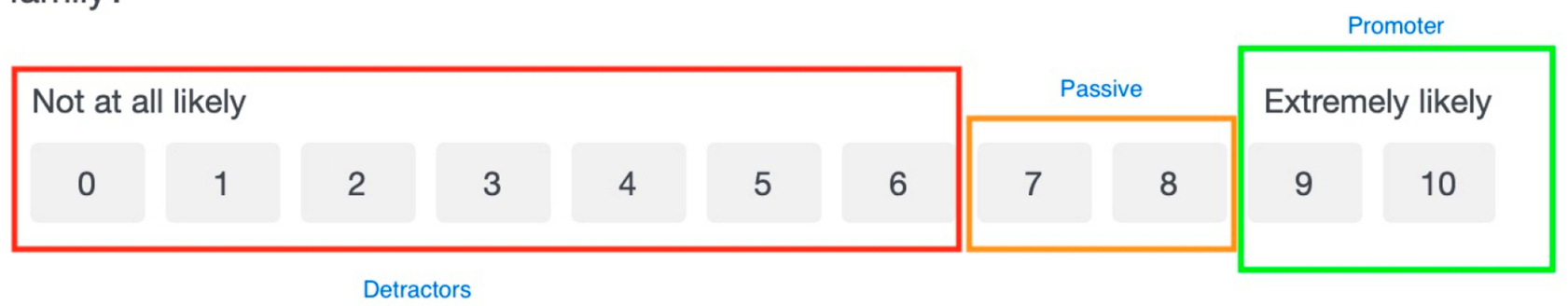

Figure I This image represents how the questions are presented to the patient. Two questions are presented on an NPS scale, first one is for the clinic for the specific diagnosis, and the other one refers to the physician who took care of them. The colored boxes and its description are there to show the reader how the NPS score is calculated. They are not present to the patients. An automatic email will trigger to the physician when either of these questions is rated/scored less than 9.

follows: 1) Rating of Provider: 0-10 and 2) Would Recommend Provider's Office (Yes, definitely; Yes, somewhat; No). The answer of "Yes, definitely" would compare with "promoters", "Yes, somewhat" with "passive", and "No" with "detractors" in the TBT method. Figure 2 shows a diagram of the patient visit process to the clinic that describes the two methods.

\section{Results}

A total of 1708 patients were seen in the clinic by all providers from February to August. During that period of time, the number of outgoing messages were compared by the regular method to the newly implemented method using the tablet with NPS. In the traditional method, the total outgoing messages during this period was 580 (34\%) outgoing messages with a total response rate of 156 out of $580(27 \%)$. In addition, the average rating score for all providers was $95 \%$ and their NPS score was 97.5 which reflects a promoter score.
When compared to the newer method, a total of 648 out of $1708(38 \%)$ surveys were collected and showed a $100 \%$ response rate compared to $27 \%$ in the traditional method. The NPS provider score in this method, TBT, was $99.2 \%$ which reflects a promoter score. In addition, the NPS clinic score was $96 \%$ which also reflects a promoter score. Two possible reasons why only 648 patients responded to this method may be due to the front desk team forgetting to ask the patient or the patient refusing to take the survey.

\section{Discussion}

The objective of our study was to look at the effectiveness of this new method of surveying patients in clinics using the NPS score versus the traditional method from a response rate and NPS score perspective. Our data showed that the latter method was very effective in capturing a higher number of responses compared to the traditional method. This higher response rate is most likely due 


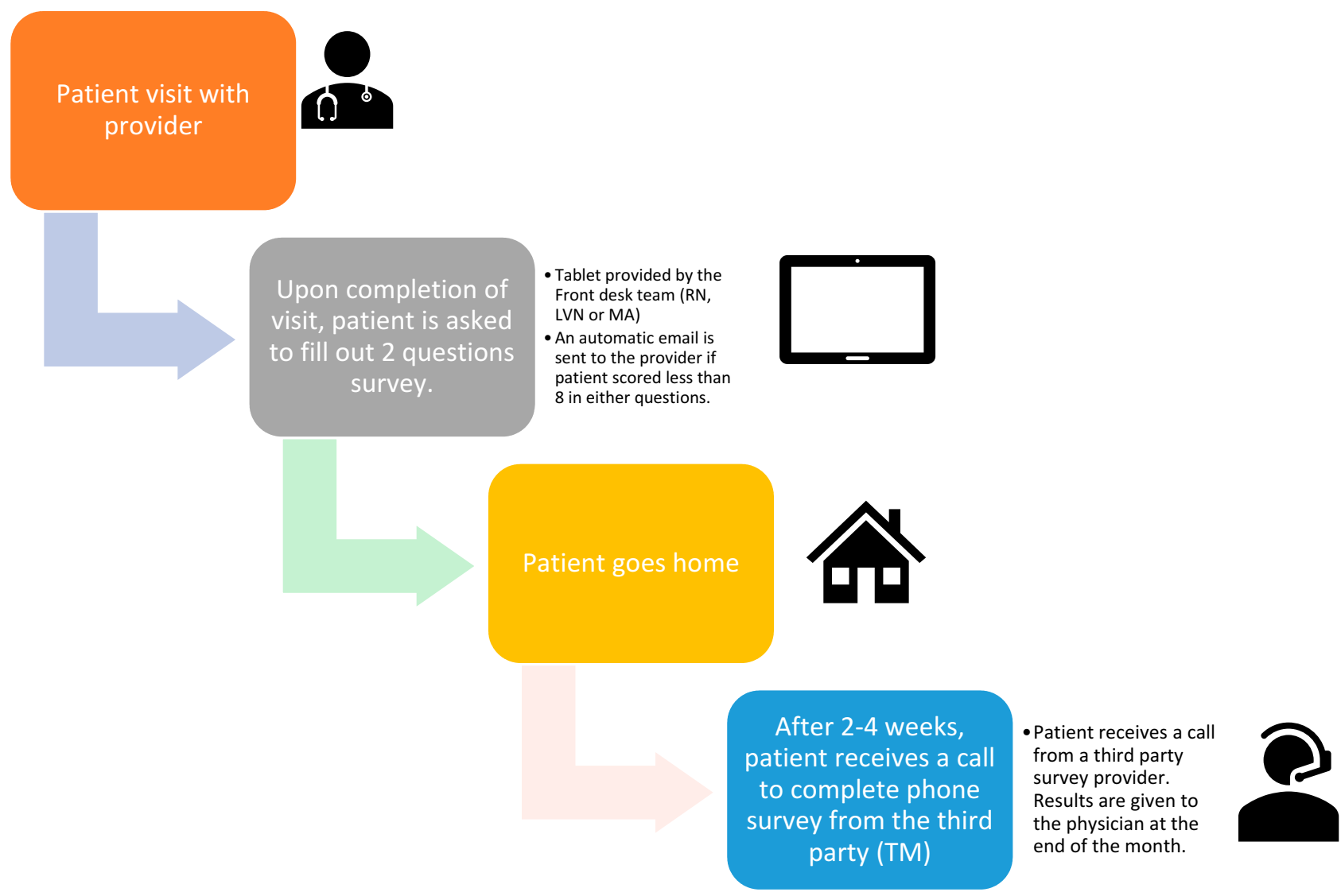

Figure $2 \mathrm{~A}$ flow diagram of the process of the patient visit and them receiving the tablet survey and/or phone survey. This figure shows how in the TM method patients usually wait 2-4 weeks until they get a phone call, email, text, etc. compared to the TBT in which response and feedback are assessed immediately post visit.

to the fact that patients were more willing to respond to a concise survey questionnaire in clinics and share their thoughts on the way out versus answering a phone call from a random number 2-4 weeks later. Although the NPS score showed promoter in both methods, the response rate was much higher in the TBT method compared to the TM.

NPS is now starting to make its way into healthcare settings to help with quality improvement. ${ }^{3,6-8,10,11}$ One of the beliefs as to why NPS has not transitioned to the social sector sooner was due to non-applicability and acceptability in the non-commercial settings. ${ }^{13}$ This belief was tested in a study performed in healthcare clinics in several lowliteracy countries (El Salvador, India, Kenya, and Nigeria), they found NPS to be a useful tool to determine patient satisfaction as well as insight into patient satisfaction. Several other healthcare studies showed the benefits of NPS for product satisfaction and its use to rate clinic satisfaction. ${ }^{7-9}$ One study by Meyer et al used NPS to gauge patient satisfaction towards physical therapy treatment for patients with progressive amyotrophic lateral sclerosis. They found that despite the disease being progressive, patients still voted heavier on the side of promoters and recommended physical therapy and the benefits it provided. ${ }^{6}$ The use of NPS continues to branch out the business world and is influencing more areas throughout the healthcare sector in a positive way. ${ }^{13}$ At the same time, to the authors' knowledge, the literature lacks data on the validity of using NPS in healthcare. Kro et $\mathrm{al}^{14}$ compared the use of NPS in healthcare to other global measures in regards to patient experience. NPS did not come as superior compared to other constructs when evaluating patient experience.

Substantial evidence is still lacking as to whether the NPS, alone, is the best means to obtain the most accurate information about patient satisfaction. Krol et al performed a study in six Dutch hospitals that used data from inpatient and outpatient surveys on 16,920 patients. ${ }^{14}$ NPS was compared with three other constructs. They found that NPS was moderate to strongly correlated with the three other constructs but showed disconnect in the "passives" category of the NPS when compared to the other three constructs. Another study by Raassens and Haans 2017 
also added value to the "passives" category of the NPS by combining the NPS with electronic "word of mouth". ${ }^{15}$ In this study, NPS strongly correlated with the traditional phone survey data. This finding parallels with our study in which both methods, TM and TBT, showed promoter scores at the end.

There were several additional findings that were encountered when comparing the tablet method NPS to the traditional method. The most prominent result was the number of completed surveys (response rate) in this study ( $27 \%$ vs $100 \%$ ). This is more likely due to timing and presentation of the survey. The tablet method also added a "live" or "dynamic" feedback system as scores would immediately be sent to the clinic supervisors and clinicians if less than an 8 was scored. This quick intel could effectively allow the supervisors or clinicians to recognize trends or actions that were not satisfying to patients and allow for them to make changes on the spot. On the contrary, the traditional method was not only performed 2-4 weeks later, but data were not returned to the physician or supervisor for at least one month. With slower feedback time, recognition of the factors causing the poor scores is more difficult to assess as the behavior or factor is not as fresh in their memory. In summary, the quick response (time) played a major role in monitoring the scores when using the TBT compared to the TM method.

Presentation is another contributing factor that may have likely played a role in the significant difference in the number of participants. A simple, 2-question survey on a touch screen tablet has a completion time of about 30 seconds and provides ease and reduced time burden to the patient. On the other hand, a phone call from an unknown number at a later date would appear to be a less desirable form of contact as it may disrupt a patient at an inconvenient time. The traditional method was also a 9-question survey (with only 2 questions representing NPS that was used in this paper) and, therefore, required additional time burden to the patient. As this is a small, single-center study for the comparison of tablet NPS to the traditional method, future prospective research should continue to build off of the unanswered questions that arise from this study. In particular, the benefit of timing and presentations of the surveys. We believe that this study might add some value to assist future prospective studies to answer this question. The inability to identify both groups' characteristics imposes a major limitation to this study. Therefore, a future prospective study is warranted to overcome these limitations.

\section{Conclusion}

The findings of this study show that NPS on a tablet survey is able to provide a higher response rate compared to the traditional method with similar recorded patient satisfaction outcome. Future prospective studies should continue to look for comparisons of NPS vs other means of quantifying patient satisfaction as well as continue to collect data on NPS as an adjunct to traditional methods.

\section{Disclosure}

There are no conflicts of interest, sponsorships, or funding to disclose for this project.

\section{References}

1. Al-Abri R, Al-Balushi A. Patient satisfaction survey as a tool towards quality improvement. Oman Med J. 2014;29(1):3. doi:10.5001/ omj.2014.02

2. Reichheld FF. The one number you need to grow. Harv Bus Rev. 2003;81(12):46-55.

3. Company B. Companies that use net promoter; 2018. Available from: http://netpromotersystem.com/about/companies-using-nps.aspx. Accessed May 6, 2020.

4. Burroughs TE, Waterman BM, Cira JC, Desikan R, Claiborne Dunagan W. Patient satisfaction measurement strategies: a comparison of phone and mail methods. Jt Comm J Qual Improv. 2001;27 (7):349-361. doi:10.1016/s1070-3241(01)27030-8

5. Bible JE, Shau DN, Kay HF, Cheng JS, Aaronson OS, Devin CJ. Are low patient satisfaction scores always due to the provider? Spine. 2018;43(1):58-64. doi:10.1097/BRS.0000000000001453

6. Meyer R, Spittel S, Steinfurth L, et al. Patient-reported outcome of physical therapy in amyotrophic lateral sclerosis: observational online study. JMIR Rehabil Assist Technol. 2018;5(2):e10099. doi:10.2196/10099

7. Stein N, Brooks K. A fully automated conversational artificial intelligence for weight loss: longitudinal observational study among overweight and obese adults. J Med Internet Res. 2017;19(11):4.

8. Wilberforce M, Poll S, Langham H, Worden A, Challis D. Measuring the patient experience in community mental health services for older people: a study of the net promoter score using the friends and family test in England. Int $J$ Geriatr Psychiatry. 2019;34(1):31-37. doi:10.1002/gps.4978

9. Powell RE, Stone D, Hollander JE. Patient and health system experience with implementation of an enterprise-wide telehealth scheduled video visit program: mixed-methods study. JMIR Med Inform. 2018;6 (1):e10. doi:10.2196/medinform.8479

10. Busby M, Matthews R, Burke F, Mullins A, Shumacher K. Is any particular aspect of perceived quality associated with patients tending to promote a dental practice to their friends and colleagues? $\mathrm{Br}$ Dent J. 2015;218(6):E12. doi:10.1038/sj.bdj.2015.229

11. Kinney WC. A simple and valuable approach for measuring customer satisfaction. Otolaryngol Head Neck Surg. 2005;133(2):169-172. doi:10.1016/j.otohns.2005.03.060

12. HCAHPS: patients' Perspectives of Care Survey; 2017. Available from: https://www.cms.gov/Medicare/Quality-Initiatives-PatientAssessment-Instruments/HospitalQualityInits/HospitalHCAHPS. html. Accessed May 6, 2020. 
13. Koladycz R, Fernandez G, Gray K, Marriott H. The Net Promoter Score (NPS) for insight into client experiences in sexual and reproductive health clinics. Glob J Health Sci. 2018;6(3):413-424.

14. Krol MW, de Boer D, Delnoij DM, Rademakers JJ. The net promoter score-an asset to patient experience surveys? Health Expect. 2015;18 (6):3099-3109.
15. Raassens N, Haans H. NPS and online WOM: investigating the relationship between customers' promoter scores and eWOM behavior. $J$ Ser Res. 2017;20(3):322-334. doi:10.1177/1094670517696965

\section{Publish your work in this journal}

Patient Related Outcome Measures is an international, peer-reviewed, open access journal focusing on treatment outcomes specifically relevant to patients. All aspects of patient care are addressed within the journal and practitioners from all disciplines are invited to submit their work as well as healthcare researchers and patient support groups.

Submit your manuscript here: http://www.dovepress.com/patient-related-outcome-measures-journal
The manuscript management system is completely online and includes a very quick and fair peer-review system. Visit http://www. dovepress.com/testimonials.php to read real quotes from published authors. 